\title{
Distribuição, diâmetro de gotas e fitoxicidade de herbicidas aplicados em mudas de eucalipto com pontas de indução de $\operatorname{ar}^{1}$
}

\author{
Distribution, droplet diameter and phytotoxicity of herbicides applied in eucalyptus \\ seedlings with air induction nozzles
}

\begin{abstract}
Bruna Pires da Silva ${ }^{2}$, Ângela Aparecida Machado ${ }^{3}$, Edson Diniz da Fonseca ${ }^{4}$, Marcelo da Costa Ferreira $^{3}$
\end{abstract}

Resumo - As pontas de pulverização são responsáveis pela formação das gotas, sendo que cada tipo de ponta exerce uma função diferente, com características próprias relacionadas à deposição de gotas de acordo com alvo que se deseja atingir. Este trabalho teve como objetivo avaliar a distribuição, diâmetro de gotas e fitotoxicidade dos herbicidas glyphosate e isoxaflutole, aplicados em mudas de eucalipto com pontas de indução de ar (AIUB 04 e TTI 110 04). O espectro do diâmetro de gotas foi determinado em analisador de tamanho de partículas por difração de luz laser. Os perfis de distribuição volumétrica foram avaliados em mesa de deposição, para a coleta da calda pulverizada. As avaliações visuais da fitotoxicidade dos herbicidas foram realizadas aos 7, 14, 21 e 28 dias após a aplicação. Ao final do período experimental determinou-se a massa de matéria seca de caule e folhas. A ponta de TTI 11004 teve maior diâmetro mediano volumétrico (DMV), menor percentual de gotas menores que $100 \mu \mathrm{m}$ e menor coeficiente de uniformidade de gotas em comparação com a ponta AIUB 04, independentemente da calda utilizada. Para a ponta de pulverização modelo TTI 110 04, os espaçamentos de 0,45 e $0,75 \mathrm{~cm}$ apresentaram melhor uniformidade (coeficiente de variação menor que 10\%). O modelo AIUB 04 não resultou em nenhum coeficiente de variação aceitável. A aplicação de glyphosate com a ponta AIUB 04 aumentou a fitointoxicação. O herbicida isoxaflutole mostrou-se seletivo ao eucalipto.

Palavras-chaves: tecnologia de aplicação, espaçamento entre pontas, seletividade, caracterização de gotas

\begin{abstract}
The spray nozzles are responsible for the formation of droplets, each nozzle type exerts a different function, with its own characteristics related to the deposition of droplets according to the desired target. This study aimed to evaluate the distribution, droplet diameter and phytotoxicity of glyphosate and isoxaflutole herbicides applied in eucalyptus seedlings with air induction nozzles (AIUB 04 and TTI 110 04). The spectrum of droplet diameter was determined by particle size analyzer by laser light diffraction. The volumetric distribution was evaluated in deposition table to collect the sprayed volume. The visual assessments of phytotoxicity of the herbicides were carried out at 7,14,21, and 28 days after application. At the end of the experiment it was determined the dry mass of stem and leaves. The TTI 11004 nozzle had greater volumetric

\footnotetext{
${ }^{1}$ Recebido para publicação em 20/06/2014 e aceito em 01/08/2015.

2 Doutoranda, Programa de Produção Vegetal, Faculdade de Ciências Agrárias e Veterinárias/UNESP - câmpus Jaboticabal. E-mail: <brunapiresagro@yahoo.com.br>.

${ }^{3}$ Faculdade de Ciências Agrárias e Veterinárias/UNESP - câmpus Jaboticabal.

${ }^{4}$ Suzano Papel e Celulose
} 
median diameter (VMD), lower percentage of droplets smaller than $100 \mu \mathrm{m}$ and lower uniformity coefficient of drops compared to the AIUB 04 nozzle. For the spray nozzle model TTI 11004 , the spacings of 0.45 and $0.75 \mathrm{~cm}$ showed better uniformity (variation coefficient lower than $10 \%$ ). The model AIUB 04 resulted in no acceptable coefficient of variation. The application of glyphosate with the AIUB 04 nozzle increased phytotoxicity. The herbicide isoxaflutole was shown to be selective to eucalyptus.

Keywords: application technology, spacing between nozzles, selectivity, characterization of drops

\section{Introdução}

As plantas daninhas constituem um dos principais problemas enfrentados na cultura do eucalipto, por causar redução na produtividade e aumento dos custos de produção, devido à grande demanda de mão de obra e ao impacto do controle químico no ambiente (Tuffi Santos et al., 2006). A redução da produtividade tem sido atribuída à competição entre eucalipto e plantas daninhas por água, luz e nutrientes, e ainda ao efeito alelopático das infestantes sobre o desenvolvimento da cultura.

O controle químico das plantas daninhas tem sido um método bastante empregado, pois permite resultados mais rápidos e eficientes, porém, para que haja sucesso na aplicação de herbicidas, é preciso atingir o alvo desejado. Para uma adequada cobertura da área pelo produto é necessário conhecer as características de deposição proporcionadas pelo equipamento, produto e forma de aplicação (Ferreira et al., 2009).

A aplicação de herbicidas pode ser realizada em pré e/ou pós-emergência das plantas daninhas. Dentre os herbicidas utilizados na cultura do eucalipto, destacam-se o glyphosate e o isoxaflutole. O glyphosate é um herbicida sistêmico de ação total, que inibe a enzima EPSP sintetase (ou EPSPS), e impede que a planta forme os aminoácidos fenilalanina, tirosina e triptofano, utilizados para a síntese de proteínas e, também, em alguns metabólitos secundários, como vitaminas, lignina e hormônios (Bradshaw et al., 1997). O glyphosate é um herbicida de amplo espectro, de curto período residual e pode ser aplicado na fase de pós- emergência das plantas daninhas (Malik et al.,1989). É um herbicida não seletivo ao eucalipto, sendo o contato dessas moléculas com a cultura, principalmente via deriva, altamente indesejado (Tuffi Santos et al., 2006). O isoxaflutole é um herbicida sistêmico, que, apesar de ser seletivo ao eucalipto, pode provocar alguns sintomas de fitointoxicação. Seu mecanismo de ação baseia-se na inibição da síntese de carotenoides. Uma vez no solo, na água e na planta é rapidamente convertido em diquetonitrila (molécula biologicamente ativa). Exerce controle efetivo de monocotiledôneas e algumas dicotiledôneas (Silva e Silva, 2007).

As pontas de pulverização com indução de ar são bastante utilizadas na aplicação de glyphosate e isoxaflutole, e também de outros herbicidas, por produzirem gotas grandes, com bolhas de ar em seu interior, o que lhe confere alta massa e baixa densidade - combinação de extrema importância para a redução da deriva (Viana et al., 2007). Alguns trabalhos são realizados para avaliar a melhor forma de distribuição satisfatória destas gotas, visando um melhor controle das plantas daninhas. Porém, na maioria destes trabalhos, os parâmetros são avaliados apenas com "água pura", e não com a calda herbicida.

Ainda, os efeitos de fitotoxicidade de herbicidas sobre as plantas de eucalipto também não são totalmente conhecidos, visto que, muitas vezes, podem ocorrer erros durante a aplicação do herbicida, que podem ocasionar a deposição direta do produto sobre as plantas de eucalipto, em aplicações realizadas em pósemergência da cultura.

Dessa forma, o trabalho teve como objetivo avaliar a distribuição, diâmetro de gotas e fitotoxicidade dos herbicidas glyphosate e isoxaflutole, aplicados em mudas de eucalipto com pontas de indução de ar. 


\section{Material e Métodos}

O estudo foi conduzido no Laboratório de Ciências das Plantas Daninhas, no Departamento de Fitossanidade da UNESP, Câmpus de Jaboticabal.

$\mathrm{O}$ delineamento utilizado foi $\mathrm{O}$ inteiramente casualizado (DIC), em esquema fatorial $2 \times 3$, com quatro repetições. O primeiro fator representou as pontas com indução de ar (AIUB 04 e TTI 110 04), e o segundo fator os tratamentos com herbicidas glyphosate $-720 \mathrm{~g}$ $\mathrm{ha}^{-1}$ e.a. $\left(1,0 \mathrm{~L}\right.$ p.c. $\left.\mathrm{ha}^{-1}\right)$ e isoxaflutole $-150 \mathrm{~g}$ i.a. ha ${ }^{-1}\left(200\right.$ g p.c. ha $\left.{ }^{-1}\right)$, e a testemunha com água. $\mathrm{O}$ volume de calda adotado foi equivalente a $400 \mathrm{~L} \mathrm{ha}^{-1}$. A pulverização foi acionada com ar comprimido, através de $\mathrm{CO}_{2}$, e a pressão, mantida constante com auxílio de um regulador de pressão, a 3,0 bar.

O espectro de gotas foi determinado com analisador de diâmetro de partículas por difração de raios laser (Mastersizer $\mathrm{S}^{\circledR}$ versão 2.19). Nesse equipamento, uma unidade óptica determina o diâmetro das gotas do espectro pulverizado, por meio do desvio de trajetória sofrido pelo laser ao atingi-las. Quanto menor a partícula, maior é o grau de difração que o raio de luz sofre (Etheridge et al., 1999). Conforme recomendações do fabricante, o equipamento foi ajustado para avaliar gotas de 0,5 a $900 \mu \mathrm{m}$ (lente de $300 \mathrm{~mm}$ ).

Utilizou-se um oscilador para que o jato de calda atravessasse transversalmente o laser durante a leitura pelo aparelho. O tempo despendido pelo oscilador para mover-se de um extremo ao outro do jato aplicado foi calibrado para 3 segundos. Cada leitura do laser foi realizada com intervalo de 2 milissegundos, totalizando 500 leituras por segundo.

Foram determinados os parâmetros: diâmetro mediano volumétrico (DMV), uniformidade do espectro de gotas (coeficiente) e porcentagem do volume aplicado, das gotas com diâmetro inferior a $100 \mu \mathrm{m}(\% \mathrm{~V}<100$ $\mu \mathrm{m})$. A avaliação do perfil de distribuição volumétrica foi realizada em mesa de deposição composta por uma chapa de metal corrugada, formando 67 canaletas em V, separadas de 2,5 $\mathrm{cm}$ entre si, totalizando $167,5 \mathrm{~cm}$ de largura.

$\mathrm{Na}$ parte inferior da mesa de deposição foram colocados tubos de ensaio de $100 \mathrm{~mL}$ para coleta da calda pulverizada, sendo um tubo para cada canaleta.

A ponta de pulverização foi posicionada no centro da mesa, de modo que o jato fosse lançado na posição vertical, com $40 \mathrm{~cm}$ de altura, segundo recomendações da FAO (1998). O perfil de distribuição volumétrica foi avaliado para cada tratamento. A pulverização foi realizada até que os tubos de ensaio das canaletas centrais (que recebem maior quantidade de calda) atingissem $90 \%$ do limite máximo de volume. Em seguida, foi registrado o volume de calda contido em cada tubo de ensaio. O perfil de distribuição volumétrica foi determinado com base na média dos volumes coletados nas quatro repetições para cada calda e pontas de pulverização. $\mathrm{O}$ perfil de distribuição volumétrica obtido foi usado para determinar, em planilha eletrônica (Microsoft Excel), os espaçamentos entre bicos a serem utilizados numa barra de pulverização.

A uniformidade de distribuição ao longo da faixa aplicada foi avaliada por meio do coeficiente de variação (FAO, 1998), sendo este aceitável para a uniformidade de distribuição de até $10 \%$.

Para a avaliação da fitotoxicidade dos herbicidas glyphosate e isoxaflutole, foram utilizadas plantas de um clone específico, oriundo de cruzamento das espécies Eucalyptus grandis $x$ Eucalyptus urophylla, adquiridas em viveiro de produção de mudas comerciais (120 dias de idade), e selecionadas segundo critérios fitossanitários e nutricionais.

A aplicação dos herbicidas e da água, com cada uma das pontas, simulou uma condição de aplicação em campo em pós-plantio das mudas de eucalipto, sendo a aplicação realizada sobre as mudas de eucalipto. Foram realizadas avaliações visuais de controle (fitointoxicação) através de notas percentuais, aos 7, 14, 21 e 28 dias após a aplicação (DAA), constituindo uma nota geral por repetição. 
Foram atribuídas notas percentuais em relação à testemunha, sendo considerada zero a ausência de sintomas e 100 a morte da planta (SBCPD, 1995). Ao final do período experimental (30 DAA), as plantas foram coletadas, separadas em caule e folhas, e colocadas para secar em estufa à $65^{\circ} \mathrm{C}$ com circulação forçada de ar, até atingirem massa constante, para a obtenção da massa de matéria seca de caule e folha.

Os resultados foram submetidos à análise de variância ANOVA a $5 \%$ de probabilidade e as médias comparadas pelo teste de Tukey a 5\% de probabilidade. Para a determinação do espaçamento entre bicos, foram estabelecidas as equações de regressão, considerando a relação do espaçamento entre bicos e seus respectivos coeficientes de variação.

\section{Resultados e Discussão}

A uniformidade do espectro de gotas não foi alterada pelas diferentes caldas e modelos de pontas avaliadas. Contudo, o diâmetro mediano volumétrico (DMV) e a porcentagem do volume de gotas com diâmetro menor que $100 \mu \mathrm{m}(\% \mathrm{~V}$ $<100 \mu \mathrm{m})$ diferiram de acordo com a calda e a ponta de pulverização. As caldas dos herbicidas isoxaflutole, glyphosate e o tratamento contendo apenas água, apresentaram menor DMV com a ponta de pulverização AIUB 04, quando comparados com TTI 110 04, devido ao fato desta última produzir gotas com maior diâmetro, (Tabela 1). Segundo Queiroz, et al (2008), gotas maiores tendem a não serem perdidas por deriva, assegurando a eficiência na hora da aplicação de herbicidas.

Tabela 1. Diâmetro mediano volumétrico (DMV), \% de gotas $<100 \mu \mathrm{m}$, para herbicidas aplicados com pontas de indução de ar (AIUB 04 e TTI 11004).

\begin{tabular}{|c|c|c|}
\hline \multicolumn{3}{|c|}{ DMV } \\
\hline & AIUB 04 & TTI 11004 \\
\hline Isoxaflutole & $535,36 \mathrm{Bb}$ & $750,34 \mathrm{Ab}$ \\
\hline Glyphosate & $588,74 \mathrm{Ba}$ & $787,03 \mathrm{Ab}$ \\
\hline Água & $532,69 \mathrm{Bb}$ & $828,22 \mathrm{Aa}$ \\
\hline \multicolumn{3}{|c|}{$\mathrm{F}_{\text {Pontas }(\mathrm{P})}-646,146^{* *} ; \mathrm{F}_{\text {Herbicidas }(\mathrm{H})}-8,998^{* *} ; \mathrm{F}_{\mathrm{PxH}}-10,432^{* *} ;$ Desvio Padrão $-22,7673 ; \mathrm{CV}(\%)-3,39$} \\
\hline \multicolumn{3}{|c|}{$\%$ Gotas $<100 \mu \mathrm{m}$} \\
\hline & AIUB 04 & TTI 11004 \\
\hline Isoxaflutole & $5,05 \mathrm{Aa}$ & $0,84 \mathrm{Ba}$ \\
\hline Glyphosate & $4,43 \mathrm{Aa}$ & $0,79 \mathrm{Ba}$ \\
\hline Água & $5,02 \mathrm{Aa}$ & $0,79 \mathrm{Ba}$ \\
\hline \multicolumn{3}{|c|}{$\mathrm{F}_{\text {Pontas }(\mathrm{P})}-537,4986^{* *} ; \mathrm{F}_{\text {Herbicidas }(\mathrm{H})}-1,4796^{\mathrm{ns}} ; \mathrm{F}_{\mathrm{PxH}}-1,2394^{\mathrm{ns}} ;$ Desvio Padrão $-0,4254 ; \mathrm{CV}(\%)-15,086$} \\
\hline \multicolumn{3}{|c|}{ Coeficiente de Uniformidade } \\
\hline & & 1004 \\
\hline Isoxaflutole & $1,66 \mathrm{Ba}$ & $1,42 \mathrm{Aa}$ \\
\hline Glyphosate & $1,61 \mathrm{Ba}$ & $1,46 \mathrm{Aa}$ \\
\hline Água & $2,10 \mathrm{Aa}$ & $1,48 \mathrm{Aa}$ \\
\hline \multicolumn{3}{|c|}{$\mathrm{F}_{\text {Pontas }(\mathrm{P})}-50,962^{* *} ; \mathrm{F}_{\text {Herbicidas }(\mathrm{H})}-12,536^{* *} ; \mathrm{F}_{\mathrm{PxH}}-9,5766^{* *} ;$ Desvio Padrão $-0,1164 ; \mathrm{CV}(\%)-7,1816$} \\
\hline
\end{tabular}

Para o parâmetro $\% \mathrm{~V}<100 \mu \mathrm{m}$ houve diferença significativa apenas entre as pontas de pulverização utilizadas, de forma que a ponta AIUB 04 produziu maior quantidade de gotas com diâmetro inferior $100 \mu \mathrm{m}$, comparativamente com a ponta TTI 11004
(Tabela 1). As gotas com diâmetro menor que $100 \mu \mathrm{m}$ são as mais propícias à sofrerem deriva (Cunha et al., 2004). Gotas com este diâmetro ou próximo a ele, podem ser perdidas pela ação do vento ou até mesmo por evaporação (Lefebvre, 1989). Devido a estes fatores é de 
extrema importância saber qual a melhor tecnologia de aplicação a ser empregada e qual o momento correto para se realizar a aplicação.

$\mathrm{O}$ coeficiente de uniformidade de gotas não foi alterado pelas diferentes caldas (isoxaflutole, glyphosate e água), dentro de cada ponta de pulverização avaliada. Todavia, quando se comparou as duas pontas de pulverização, houve diferença significativa nos tratamentos com glyphosate e isoxaflutole, de forma que a ponta AIUB 04 apresentou maior coeficiente de uniformidade em comparação com a ponta TTI 11004 .

As pontas TTI 11004 e AIUB 04 são modelos de pontas com indução de ar, gerando gotas maiores e com baixo percentual de gotas inferiores a $100 \mu \mathrm{m}$. É extremamente importante escolher corretamente a ponta de pulverização, uma vez que existem modelos de ponta que produzem cerca de $30 \%$ de gotas menores que $100 \mu \mathrm{m}$. Normalmente são modelos sem indução de ar, como pode ser visto no trabalho de Stainier et al. (2006), em que modelos sem indução de ar variaram entre 10 e $40 \%$ de volume de gotas menores que $100 \mu \mathrm{m}$ e o modelo com indução de ar não ultrapassou $4 \%$ em nenhuma situação avaliada. A mesma relação entre pontas com indução de ar e sem indução de ar pode igualmente ser observada no trabalho de Cunha et al. (2003).

Para a ponta TTI 110 04, apenas os espaçamentos de 0,45 e $0,75 \mathrm{~cm}$ apresentaram coeficiente de variação menor que $10 \%$, o que caracteriza boa uniformidade de deposição, independentemente do produto utilizado na aplicação. Já para a ponta AIUB 04, o espaçamento de $0,35 \mathrm{~cm}$, embora com coeficiente de variação superior à $10 \%$, foi o que mais se aproximou do coeficiente de variação aceitável para aplicação terrestre $(\mathrm{CV}=10 \%)$. Assim, nas condições do presente estudo, o modelo AIUB 04 avaliado não resultou em coeficiente aceitável nos espaçamentos avaliados (Tabela 2).

Tabela 2. Espaçamento entre pontas e coeficientes de variação para diferentes pontas de pulverização utilizadas para a aplicação de herbicidas em mudas de eucalipto.

\begin{tabular}{ccccccc}
\hline \multirow{2}{*}{$\begin{array}{c}\text { Espaçamento } \\
\text { entre pontas (m) }\end{array}$} & $\begin{array}{c}\text { Coeficiente de Variação (\%) } \\
\text { glyphosate }\end{array}$ & $\begin{array}{c}\text { AIUB 04 } \\
\text { isoxaflutole }\end{array}$ & $\begin{array}{c}\text { AIUB 04 } \\
\text { água }\end{array}$ & $\begin{array}{c}\text { TTI 110 04 } \\
\text { glyphosate }\end{array}$ & $\begin{array}{c}\text { TTI 110 04 } \\
\text { isoxaflutole }\end{array}$ & $\begin{array}{c}\text { TTI 110 04 } \\
\text { água }\end{array}$ \\
\hline 0,35 & 15,4 & 13,4 & 13,2 & - & - & - \\
0,45 & - & - & - & $4,7^{*}$ & $8,1^{*}$ & $7,6^{*}$ \\
0,50 & 24,6 & 27 & 27,9 & - & - & - \\
0,75 & 58,2 & 59,4 & 59,9 & $7,5^{*}$ & $9,8^{*}$ & $9,8^{*}$ \\
1 & - & - & - & 33,7 & 34,3 & 34,4 \\
\hline
\end{tabular}

* Região de cálculo onde o coeficiente de variação é aceitável.

Quanto ao perfil de distribuição em mesa de deposição, verifica-se que a ponta de pulverização AIUB 04 apresenta jato excêntrico, ou seja, o jato é direcionado somente para um lado, enquanto que a ponta TTI 11004 apresenta deposição mais bem distribuída, decrescendo do centro para as extremidades (Figura 1). Pontas com o padrão de deposição do modelo TTI 11004 são recomendadas para trabalhar em barras, havendo sobreposição entre elas (Matuo et al., 2001), enquanto a ponta AIUB 04 pode ser disposta na extremidade da barra, devido à característica do seu jato direcionado.

Para as pontas AIUB 04 e TTI 110 04, observa-se que, à medida que se aumenta a distância entre essas pontas, o coeficiente de variação aumenta (Tabela 3) e, consequentemente, a uniformidade é perdida (Figura 2).

Os espaçamentos de 0,45 e 0,75 cm apresentaram coeficiente de variação inferior a $10 \%$ e são, portanto, indicados para a ponta TTI 110 04, dessa forma possibilitam tratar uma 
faixa de aproximadamente 55 e $65 \mathrm{~cm}$, possível, sob pena de ser necessário volume respectivamente, considerando-se uma faixa útil adicional para compensar os pontos ou as faixas de $80 \%$ (Figuras $2 \mathrm{~A}$ e 2B). O volume aplicado que receberam menor quantidade de calda numa pulverização deve ser o mais uniforme (Perecin et al., 1998).

\section{TTI 11004}

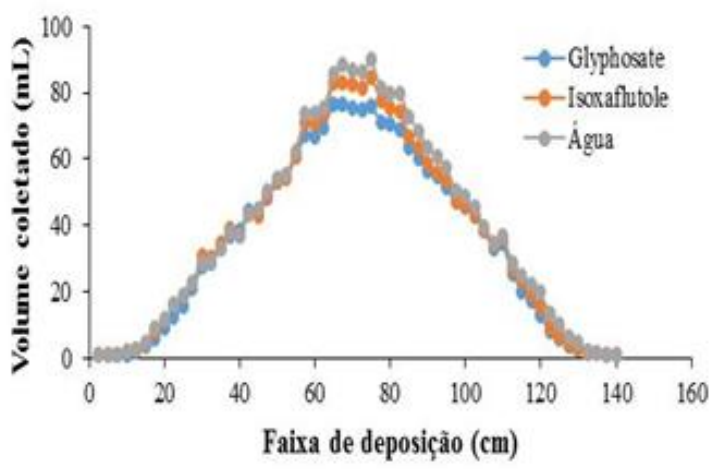

AIUB 04

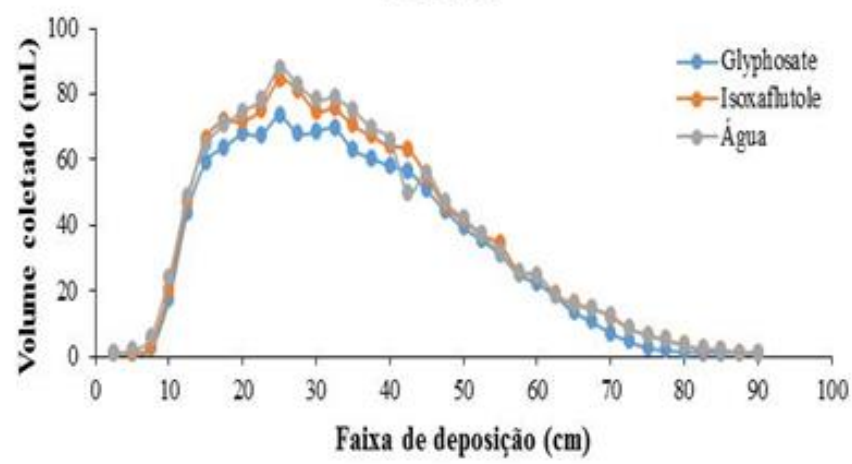

Figura 1. Perfil de distribuição das pontas AIUB 04 e TTI 11004 em mesa de deposição, considerando diferentes caldas pulverizada.

Tabela 3. Efeito da aplicação de herbicidas, com duas pontas de indução de ar, sobre a fitointoxicação, massa de matéria seca de caule e de folhas.

\begin{tabular}{|c|c|c|}
\hline \multicolumn{3}{|c|}{ Fitointoxicação em eucalipto } \\
\hline & AIUB 04 & TTI 11004 \\
\hline Isoxaflutole & $5,2125 \mathrm{Aa}$ & $7,225 \mathrm{Aa}$ \\
\hline Glyphosate & $7,6875 \mathrm{Aa}$ & $3,4875 \mathrm{Bab}$ \\
\hline Água & $0 \mathrm{Ab}$ & $0 \mathrm{Ab}$ \\
\hline \multicolumn{3}{|c|}{$\mathrm{F}_{\text {Pontas }(\mathrm{P})}-0,74^{\mathrm{ns}} ; \mathrm{F}_{\text {Herbicidas }(\mathrm{H})}-21,83^{* *} ; \mathrm{F}_{\mathrm{PxH}}-4,68^{*} ;$ Desvio Padrão $-2,07 ; \mathrm{CV}(\%)-52,65$} \\
\hline \multicolumn{3}{|c|}{ Massa de matéria seca de caule $(\mathrm{g})$} \\
\hline & AIUB 04 & TTI 11004 \\
\hline Isoxaflutole & 4,312 Aab & 4,495 Aab \\
\hline Glyphosate & $3,618 \mathrm{Ab}$ & $4,130 \mathrm{Ab}$ \\
\hline Água & 4,487 Aa & $5,182 \mathrm{Aa}$ \\
\hline \multicolumn{3}{|c|}{$\mathrm{F}_{\text {Pontas (P) }}-3,87^{\text {ns; }} ; \mathrm{F}_{\text {Herbicidas }(\mathrm{H})}-5,57^{*} ; \mathrm{F}_{\mathrm{PxH}}-0,40^{\text {ns }} ;$ Desvio Padrão $-0,57 ; \mathrm{CV}(\%)-13,19$} \\
\hline \multicolumn{3}{|c|}{ Massa de matéria seca de folhas $(\mathrm{g})$} \\
\hline & AIUB 04 & TTI 11004 \\
\hline Isoxaflutole & $6,35 \mathrm{Aa}$ & $6,65 \mathrm{Aa}$ \\
\hline Glyphosate & 6,1 Aa & $6,67 \mathrm{Aa}$ \\
\hline Água & $6,3 \mathrm{Aa}$ & 7,72 Aa \\
\hline \multicolumn{3}{|c|}{$\mathrm{F}_{\text {Pontas }(\mathrm{P})}-3,78^{\mathrm{ns}} ; \mathrm{F}_{\text {Herbicidas }(\mathrm{H})}-0,95^{\mathrm{ns}} ; \mathrm{F}_{\mathrm{PxH}}-0,73^{\text {ns }} ;$ Desvio Padrão $-0,57 ; \mathrm{CV}(\%)-13,19$} \\
\hline
\end{tabular}

Na Tabela 3 estão apresentadas as notas médias de fitointoxicação causada pela aplicação de herbicidas com as duas pontas. Para as notas médias de fitointoxicação, houve diferença entre as pontas de pulverização apenas para o herbicida glyphosate, de forma que a ponta AIUB 04 promoveu maior nota de dano que a promovida pela ponta TTI 110 04, o que pode ser explicado pela característica do jato de aplicação. 

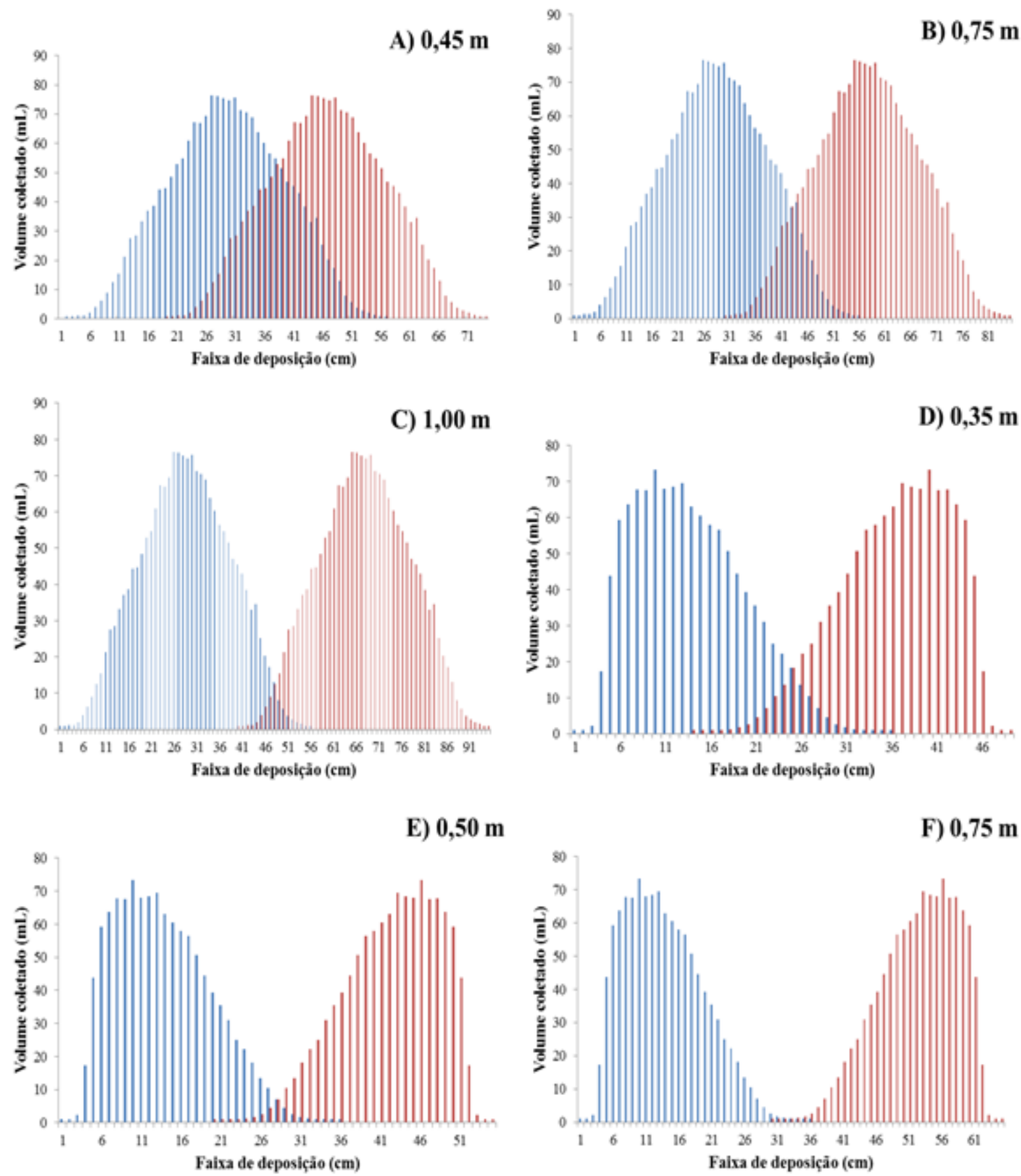

Figura 2. Sobreposição da calda por duas pontas de pulverização: modelo TTI 11004 espaçadas em A - 0,45 m, B - 0,75 m e C - 1,0 m, e modelo AIUB 04 espaçadas em D - 0,35 m, E- 0,50 m e F - 0,75 m.

A ponta AIUB 04 possui um jato excêntrico, que promoveu a concentração inicial do ingrediente ativo herbicida na muda. As pontas de pulverização de jato excêntrico são aquelas que possuem formato de jato

direcionado somente para um lado. $\mathrm{O}$ fato do herbicida glyphosate não ser seletivo ao eucalipto, aliado à característica do jato excêntrico da ponta AIUB 04, podem ter promovido sintomas visuais iniciais mais 
acentuados que os observados nos demais tratamentos. Entretanto, todas as notas visuais obtidas classificaram os sintomas de fitointoxicação como sintomas leves (SBCPD, 1995).

Para a ponta de pulverização AIUB 04, os efeitos dos herbicidas glyphosate e isoxaflutole diferiram da testemunha (água), mas não diferiram entre si. Já para a ponta TTI 110 04, os efeitos promovidos pelo herbicida isoxaflutole diferiram da testemunha, e foram estatisticamente semelhantes aos efeitos promovidos pelo glyphosate (Tabela 3 ).

Ainda que foram detectados alguns sintomas visuais de danos leves às mudas de eucalipto (notas inferiores à 10), foi possível observar uma completa recuperação destes sintomas nas plantas ao final das avaliações (28 dias após a aplicação dos tratamentos) (dados não apresentados). Entretanto, mesmo sem apresentarem sintomas visuais de fitointoxicação ao final do período experimental, a utilização do glyphosate afetou sensivelmente o crescimento das mudas de eucalipto, conforme observado na avaliação da massa de matéria seca de caule (Tabela 3).

Resultados semelhantes quanto à redução no acúmulo de massa de matéria seca também foram observados por Tuffi Santos et al. (2007). Segundo Carvalho et al. (2009), nem sempre os sintomas de intoxicação das folhas relacionam-se com a diminuição no incremento de massa de matéria seca, uma vez que alguns herbicidas, ainda que não provoquem sintomas visíveis de intoxicação na planta, podem comprometer o seu crescimento (desenvolvimento).

Para a massa de matéria seca de caule (Tabela 3), não houve diferença estatística entre o efeito promovido pelas pontas avaliadas. Independentemente da ponta de pulverização utilizada, o glyphosate foi o herbicida que diferiu da testemunha (água), promovendo redução na produção de massa de matéria seca de caule, por ter, possivelmente, causado uma redução no crescimento das plantas. A redução no crescimento das plantas devido à redução acentuada nos níveis dos aminoácidos aromáticos (fenilalanina, tirosina e triptofano), que ocorre logo após a aplicação do herbicida glyphosate (Silva et al., 2007).

Embora algumas diferenças tenham sido detectadas na análise estatística, os resultados obtidos para a massa de matéria seca de caule foram muito semelhantes, mesmo para $o$ herbicida glyphosate que não é seletivo ao eucalipto. A seletividade de herbicidas é a combinação de mecanismos biológicos e tecnológicos que permitem a proteção de uma cultura do efeito fitotóxico de um herbicida aplicado sobre ela, causando uma injúria aceitável agronômica e economicamente (Velini et al., 2000; Carvalho et al., 2009).

Já para a massa de matéria seca de folhas, não foram detectadas diferenças entre o efeito das pontas de pulverização nem entre os herbicidas utilizados, em comparação com a testemunha (Tabela 3).

Pereira et al. (2011), avaliando a intoxicação e o desenvolvimento de plantas submetidas a subdoses de glyphosate em diferentes locais de aplicação na planta, verificaram que o glyphosate afetou negativamente o crescimento do eucalipto, diminuindo o ganho em altura das plantas e em diâmetro, corroborando os resultados obtidos no presente trabalho.

É possível que o caule possa absorver e translocar maior quantidade de herbicida para o resto da planta do que as folhas, devido à ação do produto, que interrompe o ciclo do carbono no cloroplasto, o que pode promover redução na síntese de carboidratos e, consequentemente, diminuir o transporte destes carboidratos para os drenos, diminuindo, consequentemente, o transporte do herbicida (Mcallister e Haferlie, 1985). Isto pode explicar porque o caule foi o órgão mais afetado pelo herbicida isoxaflutole, em comparação com a folha.

\section{Conclusões}

A ponta de TTI 11004 apresentou maior DMV, menor \% de gotas menores que $100 \mu \mathrm{m}$ 
e menor coeficiente de uniformidade de gotas em comparação com a ponta AIUB 04, independentemente da calda utilizada.

A aplicação de glyphosate com a ponta AIUB 04 promoveu maior fitointoxicação ao eucalipto que a aplicação com a ponta TTI 110 04. O herbicida glyphosate, independentemente da ponta utilizada na aplicação, foi mais danoso ao eucalipto, sendo o herbicida isoxaflutole seletivo a cultura.

\section{Referências}

BRADSHAW, L.D. et al. Perpectives on glyphosate resistence. Weed Tecnology, v.11, n.1, p.189-198, 1997.

CARVALHO, S.J.P. et al. Herbicide selectivity by differential metabolism: considerations for reducing crop damages. Scientia Agricola., v.66, n.1, p.136-142, 2009.

CUNHA, J.P.A.R. et al. Avaliação de estratégias para redução da deriva de agrotóxicos em pulverizações hidráulicas. Planta Daninha, v.21, n.2, p.325-332, 2003.

CUNHA, J.P.A.R. et al. Espectro de gotas de bicos de pulverização hidráulicos de jato plano e de jato cônico vazio. Pesquisa Agropecuária Brasileira, v.39, n.10, p.977-85, 2004.

ETHERIDGE, R.E. et al. Characterization of the spray droplet spectra and patterns of four venturi-type drift reduction nozzles. Weed Technology, v.13, n.4, p.765-70, 1999.

FERREIRA, M.C. et al. Distribuição da calda herbicida por pontas de pulverização agrícola utilizadas em áreas de reflorestamento com eucalipto. Engenharia Agrícola, v.29, n.2, p.267-276, 2009.

\begin{tabular}{|c|c|}
\hline FOOD & AGRI \\
\hline ORGANIZATION & THE \\
\hline
\end{tabular}

LEFEBVRE, A.H. Atomization and sprays. New York: Hemisphere Publishing Corporation, 1989. $421 \mathrm{p}$.
MALIK, J. et al. The herbicide glyphosate. BioFactors, v.2, n.1, p.17-25, 1989.

MATUO, T. et al. Tecnologia de aplicação e equipamentos. In: ABEAS - Curso de proteção de plantas. Módulo 2. Brasília: ABEAS; Viçosa, MG: UFV, 2001. 85 p

MCALLISTER, R.; HABERLIE, L.L. Translocation of 14C-Glyphosate and 14CO2 Labeled photoasimilates in Canada thistle (Cirsium arvense). Weed Science, v.33, n.2, p.153-159, 1985.

PERECIN, D. et al. Padrões de distribuição obtidos com bicos TF-4, TJ60-11006 e TQ15006 em mesa de prova. Pesquisa Agropecuária Brasileira, v.33, n.2, p.175, 1998.

PEREIRA, M.R.R. et al. Absorção de subdoses de glyphosate aplicados em diferentes locais de plantas de eucalipto. Revista Árvore, v.35, n.3, p.589-594, 2011.

QUEIROZ, A.A. et al. Adjuvantes e qualidade da água na aplicação de agrotóxicos. Bioscience Journal, v.24, n.4, p.8-19, 2008.

SILVA, A.A. et al. Herbicidas: classificação e mecanismo de ação. In: SILVA, A.A.; SILVA, J.F. (Eds.). Tópicos em manejo de plantas daninhas. Viçosa, MG: Universidade Federal de Viçosa, 2007. 367 p.

SILVA, A.A.; SILVA, J.F. Tópicos em manejo de plantas daninhas. Viçosa, MG: UFV, 2007. $367 \mathrm{p}$.

SOCIEDADE BRASILEIRA DA CIÊNCIA DAS PLANTAS DANINHAS (SBCPD). Procedimentos para instalação, avaliação e análise de experimentos com herbicidas. Londrina, $1995.42 \mathrm{p}$.

STAINIER, C. et al. Droplet size spectra and drift effect of two phenmedipham formulations and four adjuvants mixtures. Crop Protection, v.25, n.12, p.1238-1243, 2006.

TUFFI SANTOS, L.D. et al. Intoxicação de espécies de eucalipto submetidos à deriva do 
glyphosate. Planta Daninha, v.24, n.2, p.359364, 2006.

TUFFI SANTOS, L.D. et al. Morphological responses of different eucalypt clones submitted to glyphosate drift. Environmental and Experimental Botany v.59, n.1, p.11-20, 2007.

VELINI, E.D. at al. Avaliação da seletividade da mistura de oxyfluorfen e ametryne, aplicada em pré ou pós-emergência, a dez variedades de cana-de-açúcar (cana-planta). Planta Daninha, v.18, n.1, p.123-134, 2000.

VIANA, R.G. et al. Características técnicas de pontas de pulverização LA-IJC e SR-1. Planta Daninha, v.25, n.1, p.211-218, 2007. 